\title{
Effect of polymorphisms of IL-17A, -17F and MIF genes on CpG island hyper-methylation (CIHM) in the human gastric mucosa
}

\author{
TOMOMITSU TAHARA ${ }^{1}$, TOMOYUKI SHIBATA ${ }^{1}$, MASAKATSU NAKAMURA ${ }^{1}$, HIROMI YAMASHITA ${ }^{1}$, \\ DAISUKE YOSHIOKA $^{1}$, MASAAKI OKUBO ${ }^{1}$, JOH YONEMURA ${ }^{1}$, YOSHITERU MAEDA ${ }^{1}$, \\ NAOKO MARUYAMA ${ }^{1}$, TOSHIAKI KAMANO ${ }^{1}$, YOSHIO KAMIYA ${ }^{1}$, HIROSHI FUJITA ${ }^{1}$, \\ YOSHIHITO NAKAGAWA ${ }^{1}$, MITSUO NAGASAKA ${ }^{1}$, MASAMI IWATA $^{1}$, \\ ICHIRO HIRATA $^{1}$ and TOMIYASU ARISAWA ${ }^{2}$
}

\author{
${ }^{1}$ Department of Gastroenterology, Fujita Health University School of Medicine, 1-98 Dengakugakubo, \\ Kutsukake-cho, Toyoake, Aichi, 470-1192; ${ }^{2}$ Department of Gastroenterology, Kanazawa \\ Medical University, 1-1 Daigaku, Uchinadamachi, Ishikawa 920-0293, Japan
}

Received June 1, 2009; Accepted July 7, 2009

DOI: 10.3892/ijmm_00000266

\begin{abstract}
CpG island hyper-methylation (CIHM) is one of the major events in the gastric carcinogenesis and also occurs in non-neoplastic gastric mucosa. IL-17A, -17F and MIF have a crucial role in the gastric inflammationand carcinogenesis. The CIHM status in the non-cancerous gastric mucosa, in relation to IL-17A $(-197 \mathrm{G}>\mathrm{A}$, rs2275913), -17F $(7488 \mathrm{~T}>\mathrm{C}$, rs763780) and MIF $(-173 \mathrm{G}>\mathrm{C}$ and -794 tetranucleotide repeats) polymorphisms was investigated. Gastric mucosa samples were obtained from 121 cancer free subjects. CIHM of p14, p16, DAP-kinase and CDH1 genes were determined by methylation-specific polymerase chain reaction (MSP). CIHM high was defined as three or all $\mathrm{CpG}$ islands methylated. We employed the PCR-SSCP (multiplex PCR for IL-17A and -17F) method to detect the gene polymorphisms. No association were found between CIHM status and L-17A $(-197 \mathrm{G}>\mathrm{A})$, IL-17F $(7488 \mathrm{~T}>\mathrm{C})$ and MIF $(-173 \mathrm{G}>\mathrm{C})$ polymorphisms. MIF 5-CATT repeat carrier $(5 / 5+5 / 6+5 / 7)$ held a significantly higher risk of CIHM of DAP-kinase $(\mathrm{OR}=2.33,95 \% \mathrm{CI}=1.07-5.09, \mathrm{p}=0.03)$ and CIHM high $(\mathrm{OR}=3.63,95 \% \mathrm{CI}=1.31-10.08, \mathrm{p}=0.01)$. Weak association was also found between the same genotype and increased risk of CIHM of p16 $(\mathrm{OR}=2.45,95 \% \mathrm{CI}=0.90-6.68, \mathrm{p}=0.08)$
\end{abstract}

Correspondence to: Dr Tomomitsu Tahara, Department of Gastroenterology, Fujita Health University School of Medicine, 1-98 Dengakugakubo, Kutsukake-cho, Toyoake, Aichi 470-1192, Japan

E-mail: tomomiccyu@yahoo.co.jp

Abbreviations: CIHM, CpG island hyper-methylation; MIF, macrophage migration inhibitory factor; H. pylori, Helicobacter pylori; MSP, methylation-specifc PCR

Key words: $\mathrm{CpG}$ island hyper-methylation, stomach, interleukin-17, macrophage migration inhibitory factor, genetic polymorphism and $\mathrm{CDH} 1(\mathrm{OR}=2.23,95 \% \mathrm{CI}=0.94-5.32, \mathrm{p}=0.07)$. 6-CATT repeat carrier $(5 / 6+6 / 6+6 / 7)$ was significantly associated with reduced risk of $\mathrm{CIHM}$ of $\mathrm{p} 16(\mathrm{OR}=0.31,95 \% \mathrm{CI}=0.11-0.90$, $\mathrm{p}=0.03), \mathrm{CDH} 1(\mathrm{OR}=0.40,95 \% \mathrm{CI}=0.17-0.98, \mathrm{p}=0.045)$, DAP-kinase $(\mathrm{OR}=0.37,95 \% \mathrm{CI}=0.17-0.83, \mathrm{p}=0.02)$ and CIHM high $(\mathrm{OR}=0.25,95 \% \mathrm{CI}=0.09-0.74, \mathrm{p}=0.01)$. -7 -CATT repeat carrier $(6 / 7+7 / 7)$ was weakly associated with reduced risk of CIHM of p16 $(\mathrm{OR}=0.34,95 \% \mathrm{CI}=0.10-1.13, \mathrm{p}=0.08)$, DAP-kinase $(\mathrm{OR}=0.43,95 \% \mathrm{CI}=0.17-1.06, \mathrm{p}=0.07)$ and CIHM high $(\mathrm{OR}=0.38,95 \% \mathrm{CI}=0.12-1.20, \mathrm{p}=0.098)$. The present results provided the first evidence that the genetic polymorphisms MIF polymorphism is associated with CIHM status in the human gastric mucosa. Genetic polymorphisms of MIF-794-CATT repeat may be involved in methylation related carcinogenesis in the stomach.

\section{Introduction}

CpG island hyper methylation (CIHM) has been shown to be an important mechanism in gene silencing. In many kinds of cancer, several genes acquire CIHM. Meanwhile, some genes are also methylated in non-neoplastic tissues with aging, and this alteration is known as age-related methylation $(1,2)$. p16(INK4a) and p14(ARF) are involved in the negative cell cycle regulation via the $\mathrm{pRb}$ and $\mathrm{p} 53$ pathways, respectively. These two proteins have an independent first exon (exon 1a and $1 \beta$, respectively) but share exon 2 and $3(3,4)$. Methylation of p16 and p14 has been shown to be present in gastric cancer as well as premalignant lesion $(5,6)$.

E-cadherin (CDH1) is an adhesion molecule involved in tumour invasion/metastasis. Silencing of E-cadherin by promoter $\mathrm{CpG}$ methylation has also been shown in gastric cancer (7). Death-associated protein kinase (DAP-kinase) is a calcium/calmodulin-dependent serine/threonine kinase, and participates in various apoptosis systems. Methylation of DAP-kinase has been reported in many cancers (8) including gastric cancer $(9,10)$. It has also been reported that CIHM of those 4 genes are frequently occurred in non-cancerous gastric mucosa in relation to $H$. pylori infection $(7,11,12)$, histological 
or serological severity of gastritis (12) and gastric cancer occurrence (13-15). Therefore, they may be susceptible candidate genes for CIHM in the stomach.

As the possible mechanisms of CIHM, exogenous carcinogens, generated reactive oxygen and host genetic differences may influence its status (16). One of the most important factors causing CIHM in the stomach is $H$. pylori infection $(7,11,12)$, which induces chronic inflammation, causing oxidative stress to the gastric epithelium $(16,17)$. However, there is considerable variation in the extent of gastric inflammation among $H$. pylori infected patients and not all of them show same CIHM status, suggesting that some inter individual genetic difference may contribute to this process.

Interleukin-17 (IL-17) is a relatively newly described cytokine which bridges the adaptive and innate immune systems. IL-17 family members belong to a distinct category of cytokines and play a role in coordinating local tissue inflammation by inducing the release of proinflammatory and neutrophil-mobilizing cytokines (19). In addition, IL-17A and $-17 \mathrm{~F}$ share similar functions in terms of their ability to induce chemokines that are important in neutrophil recruitment and activation. Recently, Kawaguchi et al reported that the IL-17F 7488T/C (rs763780), which causes a His-to-Arg substitution at amino acid 161 (H161R) variant, influences the risk of asthma and is a natural IL-17F antagonist in the known polymorphisms of the IL-17 gene (20).

Macrophage migration inhibitory factor (MIF) was originally identified as an activity isolated from $\mathrm{T}$ lymphocytes which was capable of inhibiting the random migration of macrophages (21). MIF contributes toward an excessive inflammatory response both directly and via an induction of proinflammatory cytokine secretion (22). Polymorphisms with potential functional relevance have been identified in the MIF gene promoter; an SNP at position -173 (G to C) (23) and a tetranucleotide CATT repeat beginning at nucleotide position -794 (24) were found to be associated with altered levels of MIF gene transcription in vitro. Important roles of both IL-17 and MIF in the inflammatory response to $H$. pylori infection have been demonstrated $(25,26)$. Recently, we have also shown the potential roles of IL-17A, $-17 \mathrm{~F}$ and MIF polymorphisms in the gastric inflammation $(27,28)$ and carcinogenesis $(29,30)$.

Consequently, this study was performed to clarify whether the polymorphisms of IL-17A (-197G>A, rs2275913), -17F $(7488 \mathrm{~T}>\mathrm{C}$, rs763780) and MIF $(-173 \mathrm{C}>\mathrm{G}$ and -794 tetranucleotide repeats) influence the methylation related carcinogenesis. In this study, we investigated the prevalence of CIHM of 4 candidate genes: p14, p16, CDH1 and DAP-kinase, they have been thought to be most susceptible for methylation in the stomach (7,11-15) among non-cancerous gastric mucosa and its relation to IL-17A, IL-17F and MIF polymorphisms.

\section{Materials and methods}

Tissue samples and DNA extraction. The study population comprised 121 non-cancer subjects, attending the Endoscopy Center of Fujita Health University Hospital from January 2005 to May 2008. All the subjects underwent upper gastroscopy as part of a health check, as a secondary procedure following barium X-ray examination for suspected stomach cancer, or for the investigation of abdominal discomfort. This cohort was partly recruited from recent study investigating the association between promoter CIHM and severity of chronic gastritis (12), host genetic factors (31). Patients who had severe systemic disease, or malignancy in the stomach or other organ, who had a history of gastric surgery were excluded from the study. Patients who had a history of continuous or occasional use of non-steroidal anti-inflammatory drugs and who had ungone $H$. pylori eradication were also excluded from this study. Biopsy specimens were taken from the antrum along the greater curvature, from grossly non-pathological mucosa in all the subjects. The specimens were cut into two pieces. One of the pieces was fixed in $10 \%$ buffered formalin and embedded in paraffin for microscopic histological examination and the other part was immediately frozen and stored at $-80^{\circ}$ until use. Histological analysis of all the selected biopsy samples also showed that these samples contained more than $70 \%$ of epithelial cells. Genomic DNA was extracted directly from the frozen specimens using a standard phenol/chloroform method. H. pylori infection status was assessed by serological, histological analysis or urea breath test. Patients were diagnosed as infected when at least one of the diagnostic tests was positive. The Ethics Committee of the Fujita Health University School of Medicine approved the protocol and prior, written informed consent was obtained from all participating subjects.

\section{Bisulfite modification and methylation-specifc PCR (MSP).} To detect CIHM, we chose four candidate promoter $\mathrm{CpG}$ islands, which were thought to be most susceptible for methylation in the stomach (7,11-15): p14, p16, DAP-kinase and CDH1. For the examination of DNA methylation, genomic DNA was treated with sodium bisulfite using BislFast DNA modification kit for methylated DNA detection (Toyobo, Co., Ltd., Osaka, Japan). MSP were carried out with primers as follows: p14 methylated forward (p14 MF); 5'-gtgttaaagggcggcgtagc-3', p14 methylated reverse (p14 MR); 5'-aaaaccctcactcgcgacga-3', which amplify 122-bp product, p14 un-methylated forward (p14 UF); 5'-tttttggtgttaaagggtg gtgtagt-3', p14 un-methylated reverse (p14 UR); 5'-cacaaaaac cctcactcacaacaa-3' which amplify 132 -bp product (32), p16 methylated forward (p16 MF); 5'-ttattagagggtggggcggatcgc-3', p16 methylated reverse (p16 MR); 5'-gaccccgaaccgcgaccg taa-3', which amplify 150-bp product, p16 un-methylated forward (p16 UF); 5'-ttattagagggtggggtggattgt-3', p16 unmethylated reverse (p16 UR); 5'-caaccccaaaccacaaccataa-3', which amplify 151-bp product (33), CDH1 methylated forward (CDH1 MF); 5'-ttaggttagagggttatcgcgt-3', CDH1 methylated reverse (CDH1 MR); 5'-taactaaaaattcacctaccgac-3', which amplify 115-bp product, CDH1 un-methylated forward (CDH1 UF); 5'-taattttaggttagagggttattgt-3', CDH1 unmethylated reverse (CDH1 UR); 5'-cacaaccaatcaacaacaca-3', which amplify 97-bp product (33), DAP-kinase methylated forward (DAP-kinase MF); 5'-ggatagtcggatcgagttaacgtc-3', DAPkinase methylated reverse (DAP-kinase MR); 5'-ccc tcccaaa cgccga-3', which amplify 98-bp product, DAP-kinase unmethylated forward (DAP-kinase UF); 5'-ggaggatagttggat tgagttaatgtt-3', DAP-kinase un-methylated reverse (DAPkinase UR); 5'-caaatccctcccaaacaccaa-3', which amplify 106-bp 
product (34). An annealing temperature and times were determined using DNA from peripheral blood of a young individual without $H$. pylori infection and DNA methylated with SssI methylase (New England BioLabs Inc., Beverly, MA). The MSP was carried out in a volume of $20 \mu 1$ containing $0.1 \mu \mathrm{g}$ of bislufite-modificated DNA. The DNA was denatured at $95^{\circ} \mathrm{C}$ for $5 \mathrm{~min}$, followed by 33-35 cycles at $95^{\circ} \mathrm{C}$ for $30 \mathrm{sec}$ and $57-69^{\circ} \mathrm{C}$ according to primers for $1 \mathrm{~min}$, and $72^{\circ} \mathrm{C}$ for $1 \mathrm{~min}$ with a final extension at $72^{\circ} \mathrm{C}$ for $5 \mathrm{~min}$. MSP reactions were done using EX Taq HS (Takara Bio Inc., Shiga, Japan). PCR products $(10 \mu 1)$ were separated by electrophoresis in $2.5 \%$ agarose gels, and visualized by UV illumination using an ethdium bromide staining. CIHM was defined as the presence of positive methylation band, showing signals approximately equivalent to or greater than that of size marker (10 ng/ $\mu$ l: 100 bp DNA Ladder, Takara Bio Inc.), irrespective of the presence of un-methylated bands. Samples giving faint positive signals were analyzed a further two times and only those samples with consistent positive methylation band were considered as CIHM. In addition, we measured the fluorescence intensities of methylated bands for randomly selected 50 CHIM samples using digital densitometer (Lane Analyzer, ATTO, Tokyo, Japan), and confirmed that the fluorescence intensities of all 50 methylated bands were approximately equivalent to or greater than that of size marker (data not shown). CIHM high was also defined as three or more $\mathrm{CpG}$ islands methylated.

Genotyping of polymorphisms. Polymorphism was genotyped by PCR-SSCP method as previously described (27-30). To detect the IL-17A and $-17 \mathrm{~F}$ polymorphisms, using the primer pairs (IL-17AF, 5'-aacaagtaagaatgaaaagagg acatggt-3'; IL$17 \mathrm{AR}, 5$ '-ccccaatgaggtcatagaagaatc-3'; IL-17FF, 5'-gtg taggaacttgggctgcatcaat-3'; and IL-17FR: 5'-agtggatat gcacctcttactgcaca-3', respectively), one-tube multiplex PCR was carried out in a volume of $20 \mu \mathrm{l}$ containing $0.1 \mu \mathrm{g}$ of genomic DNA. The DNA was denatured at $96^{\circ} \mathrm{C}$ for $90 \mathrm{sec}$, followed by 35 cycles at $96^{\circ} \mathrm{C}$ for $15 \mathrm{sec}, 58^{\circ} \mathrm{C}$ for $30 \mathrm{sec}$ and $72^{\circ} \mathrm{C}$ for $45 \mathrm{sec}$, with a final extension at $72^{\circ} \mathrm{C}$ for $3 \mathrm{~min}$. Thereafter, $2 \mu 1$ of the PCR product was denatured with $10 \mu 1$ of formamide (Sigma-Aldrich Co., St. Louis, USA) at $90^{\circ} \mathrm{C}$ for $5 \mathrm{~min}$. SSCP was carried out at 6 or $12^{\circ} \mathrm{C}$ using a GenePhor DNA separation system with GeneGel Excel 12.5/24 (Amersham Biosciences Corp., USA), after which the denatured singlestrand DNA bands were detected using a DNA Silver Staining kit (Amersham Biosciences Corp.).

To detect MIF-794 CATT repeats and the G-173C polymorphism, using the primer pairs (MIFTRF, 5'-tgatccagt tgctgccttgtc-3'; MIFTRR, 5'-tccactaatggtaaactcggggac-3'; MIF173F, 5'-tctagccgccaagtggagaaca-3'; and MIF173R, 5'-act gtggtcccgccttttgtga-3', respectively), PCR was carried out in a volume of $20 \mu \mathrm{l}$ containing $0.1 \mu \mathrm{g}$ of genomic DNA. The DNA was denatured at $95^{\circ} \mathrm{C}$ for $3 \mathrm{~min}$, followed by 35 cycles at $95^{\circ} \mathrm{C}$ for $30 \mathrm{sec}, 60$ or $62^{\circ} \mathrm{C}$ for $40 \mathrm{sec}$ and $72^{\circ} \mathrm{C}$ for $45 \mathrm{sec}$, with a final extension at $72^{\circ} \mathrm{C}$ for $5 \mathrm{~min}$. Thereafter, SSCP was carried out in a similar manner as described above.

Statistical analysis. Statistical analysis was done with $\chi^{2}$ test for the comparison of CIHM in different gender and, $H$. pylori infection status. Student's t-test was used for the
Table I. Characteristics of the 121 subjects.

Variables

\begin{tabular}{lc}
\hline Age (mean SD) & $62.7 \pm 12.6$ \\
Sex (Male/female) & $69 / 52$ \\
H. pylori infection positive ratio $(\%)$ & 57 \\
Active ulcer & 14
\end{tabular}

association between CIHM and age. Logistic regression analysis with adjustment for sex, age and $H$. pylori infection status were used for the association between CIHM and two groups of different genotypes. A probability value of $<0.05$ was considered statistically significant.

\section{Results}

Characteristics of subjects. A total of 121 cancer free subjects participated in this study. The characteristics of subjects are shown in Table I. After gastroscopy, 14 subjects were diagnosed as having active peptic ulcers.

Association between CIHM and age, gender and H. pylori infection status. All 121 gastric mucosa samples were available for MSP analysis. In all subjects, CIHM was found in $45(37.2 \%)$ for $\mathrm{p} 14,37(30.6 \%)$ for $\mathrm{p} 16,54$ subjects $(44.6 \%)$ for CDH1 and $62(51.2 \%)$ for DAP-kinase. CIHM high was also found in 34 subjects $(28.1 \%)$. CIHM of DAPkinase was significantly associated with aging, while CIHM of p16, CDH1 and CIHM high were significantly associated with $H$. pylori infection status. Weak association was also found between CIHM of p14 and age (Table II).

Multivariate logistic regression analysis for relationship between CHIM and IL-17A, IL-17F and MIF polymorphisms. IL-17A (-197G >A) and IL-17F (7488T >C) polymorphisms were successfully genotyped for 120 subjects, while MIF (-173G>C) and MIF (-794-CATT repeat) polymorphisms were successfully genotyped for 115 subjects. The prevalence of IL-17A, IL-17F and MIF genotypes are shown in Table III. We did not find significant association between CIHM status and L-17A (-197G>A), IL-17F (7488T>C) and MIF (-173G>C) polymorphisms. However, concerning the MIF (-794-CATT repeat) polymorphism, we found that 5-CATT repeat carrier $(5 / 5+5 / 6+5 / 7)$ held a significantly higher risk of CIHM of DAP-kinase $(\mathrm{OR}=2.33,95 \% \mathrm{CI}=1.07-5.09, \mathrm{p}=0.03)$ and CIHM high $(\mathrm{OR}=3.63,95 \% \mathrm{CI}=1.31-10.08, \mathrm{p}=0.01)$. Weak association was also found between the same genotype and increased risk of CIHM of p16 $(\mathrm{OR}=2.45,95 \% \mathrm{CI}=0.90-6.68$, $\mathrm{p}=0.08)$ and $\mathrm{CDH} 1(\mathrm{OR}=2.23,95 \% \mathrm{CI}=0.94-5.32, \mathrm{p}=0.07)$. On the other hand, 6-CATT repeat carrier $(5 / 6+6 / 6+6 / 7)$ was significantly associated with reduced risk of CIHM of p16 $(\mathrm{OR}=0.31,95 \% \mathrm{CI}=0.11-0.90, \mathrm{p}=0.03), \mathrm{CDH} 1 \quad(\mathrm{OR}=0.40$, $95 \% \mathrm{CI}=0.17-0.98, \mathrm{p}=0.045)$, DAP-kinase $(\mathrm{OR}=0.37,95 \%$ $\mathrm{CI}=0.17-0.83, \mathrm{p}=0.02)$ and $\mathrm{CIHM}$ high $(\mathrm{OR}=0.25,95 \%$ $\mathrm{CI}=0.09-0.74, \mathrm{p}=0.01)$. We also found that -7 -CATT repeat carrier $(6 / 7+7 / 7)$ was weakly associated with reduced risk of CIHM of p16 (OR=0.34, 95\% CI=0.10-1.13, p=0.08), 
Table II. CIHM status of 4 promoter CpG islands in gastric mucosa, in relation to gender, age and $H$. pylori infection status.

\begin{tabular}{|c|c|c|c|c|c|}
\hline \multirow[b]{2}{*}{ Variables (n) } & \multirow{2}{*}{$\frac{\text { Age }^{\mathrm{a}}}{(\text { mean } \pm \mathrm{SD})}$} & \multicolumn{2}{|c|}{ Gender } & \multicolumn{2}{|c|}{ H. pylori infection status ${ }^{\mathrm{b}}$} \\
\hline & & Male & Female & H.pylori (-) & H.pylori $(+)$ \\
\hline \multicolumn{6}{|l|}{ pl4 } \\
\hline Un-methylated (76) & $61.0 \pm 12.8$ & 41 & 35 & 35 & 41 \\
\hline Methylated (45) & $65.5 \pm 11.8$ & 28 & 17 & 17 & 28 \\
\hline \multicolumn{6}{|l|}{ pl6 } \\
\hline Un-methylated (84) & $63.3 \pm 13.4$ & 48 & 36 & 49 & 35 \\
\hline Methylated (37) & $61.4 \pm 10.6$ & 21 & 16 & 3 & 34 \\
\hline \multicolumn{6}{|l|}{$\mathrm{CDH1}$} \\
\hline Un-methylated (67) & $63.7 \pm 13.2$ & 39 & 28 & 41 & 26 \\
\hline Methylated (54) & $61.5 \pm 11.7$ & 30 & 24 & 11 & 43 \\
\hline \multicolumn{6}{|l|}{ DAP kinase } \\
\hline Un-methylated (59) & $60.8 \pm 12.3$ & 31 & 28 & 27 & 32 \\
\hline Methylated (62) & $64.5 \pm 12.7$ & 38 & 24 & 25 & 37 \\
\hline \multicolumn{6}{|l|}{ CIMH high } \\
\hline CIMH high(-) (87) & $64.4 \pm 9.9$ & 50 & 37 & 47 & 40 \\
\hline CIMH high(+) (34) & $62.1 \pm 13.5$ & 19 & 15 & 5 & 29 \\
\hline
\end{tabular}

CIHM high was defined as three or more $\mathrm{CpG}$ islands were methylated. ${ }^{\mathrm{a}} \mathrm{p} 14 ; \mathrm{p}=0.06$, DAP-kinase; $\mathrm{p}=0.10$ : Student's t-test. ${ }^{\mathrm{b}} \mathrm{p} 16$, CDH1; $\mathrm{p}<0.0001$, CIHM high; $\mathrm{p}=0.0003: \chi^{2}$.

DAP-kinase $(\mathrm{OR}=0.43,95 \% \mathrm{CI}=0.17-1.06, \mathrm{p}=0.07)$ and CIHM high $(\mathrm{OR}=0.38,95 \% \mathrm{CI}=0.12-1.20, \mathrm{p}=0.098)$. No association was found between CHIM status and homozygote genotypes of each repeats (-794-CATT 5/5, 6/6, and 7/7) (data not shown).

\section{Discussion}

Our present result showed that CIHM of DAP-kinase was significantly associated with aging, while CIHM of p16, CDH1 and CIHM high were significantly associated with $H$. pylori infection status. It has been reported that CIHM is observed in non-neoplastic gastrointestinal tissues as age related phenomenon $(1,2,35)$. There have also been reports showing that $H$. pylori infection is the most predisposing factor for gene methylation in the stomach $(7,11,12)$. Thus, our present result is in line with other studies and seems reasonable.

Although, the mechanisms of CIHM are unknown, several factors may contribute to this methylation, such as exogenous carcinogens, generated reactive oxygen and host genetic differences (31). One of the most important factors causing CIHM in the stomach is $H$. pylori infection $(7,11,12)$, which induces chronic inflammation, causing oxidative stress to the gastric epithelium $(16,17)$. Indeed, the methylation of certain genes in non-neoplastic gastric mucosa correlate with $H$. pylori related histological or serological severity of gastritis (12) and gastric cancer occurrence (13-15). Thus, this epigenetic change is thought to be an early step in gastric carcinogenesis. However, not all patients with $H$. pylori infection show CIHM and develop gastric cancer. This difference may be attributed to some genetic factors.

In our study, MIF 5-CATT repeat carrier was significantly associated with higher risk of CIHM of DAP-kinase and CIHM high. While, the 6-CATT repeat carrier was significantly associated with reduced risk of CIHM of p16, CDH1, DAP-kinase and CIHM high. Weak association was also found between the MIF-794-CATT 5 repeat carrier and increased risk of CIHM of p16 and CDH1, -794-CATT 7 repeat carrier and reduced risk of CIHM of p16, DAP-kinase and CIHM high.

MIF was originally identified as an activity isolated from $\mathrm{T}$ lymphocytes that was capable of inhibiting the random migration of macrophages $(36,37)$. Many studies have shown MIF to be a key modulator of many chronic and disabling human disorders, such as rheumatoid arthritis (38), sepsis (39), acute respiratory syndrome (40), and atopic diseases $(41,42)$. Several studies have also shown significant associations of MIF gene promoter functional polymorphisms with cystic fibrosis (43), psoriasis (44) and atopic disorders (45). An important role of MIF in gastric disorders has also been shown in gastric inflammation (26), ulcer (46) and carcinogenesis (47). It is well known that a polarized T helper 1 immune response occurs in $H$. pylori infection (29). MIF directly activates or promotes cytokine expression [TNF (48), IL-2 (49), IL-8 (50) and INF- $\gamma$ (51)]. Furthermore, Xia et al have reported that $H$. pylori stimulates MIF release in monocytes and expression of MIF in gastric mucosa (26). We have recently shown the potential association between MIF gene promoter functional polymorphisms and gastric cancer 


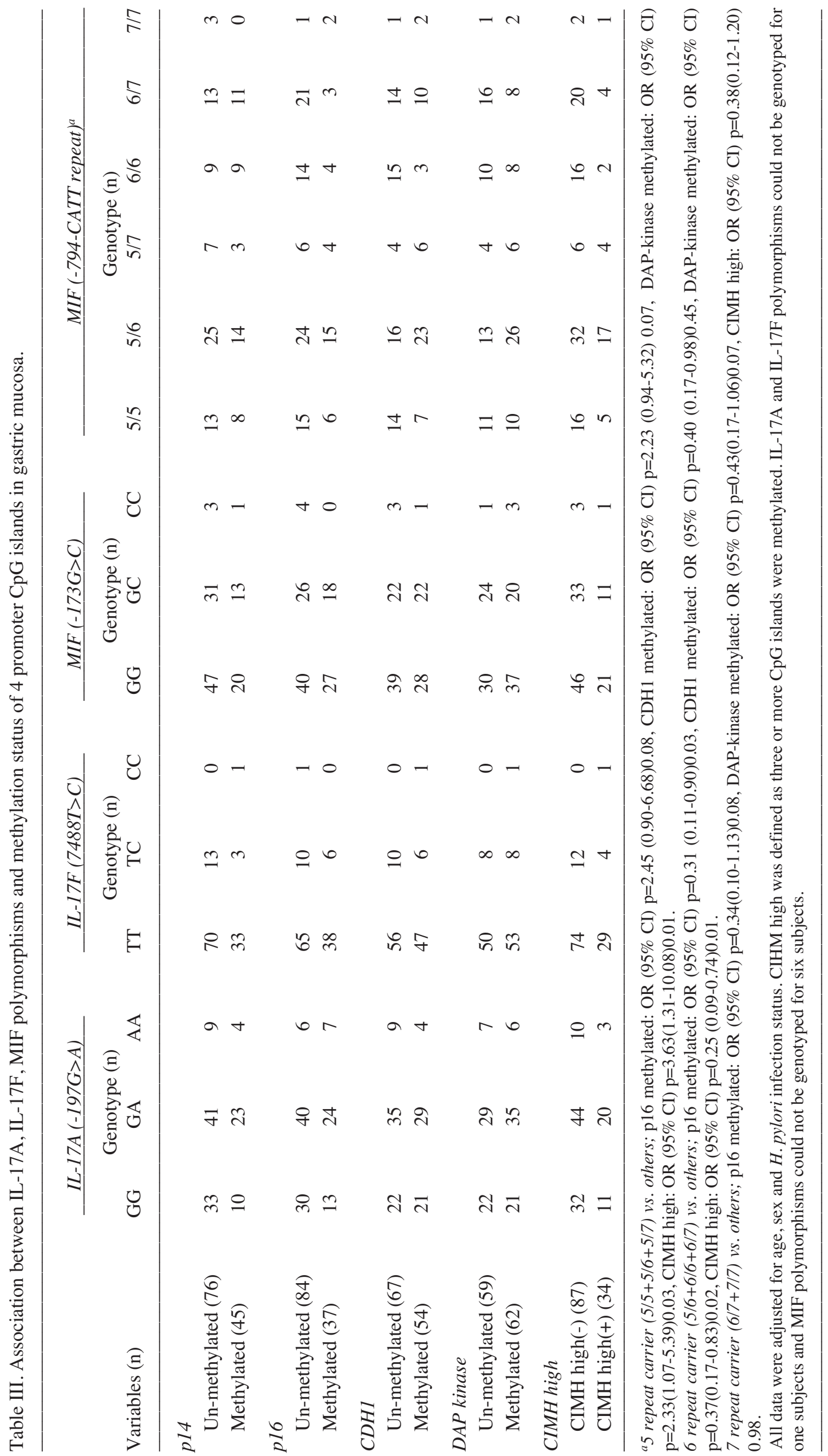


(29) and $H$. pylori related chronic gastritis (27). Since the important roles that MIF plays with respect to gastric inflammation and carcinogenesis, it seems reasonable to expect that MIF gene promoter functional polymorphisms is also associated with CIHM status in the gastric mucosa.

From the functional perspective, promoter sequence analysis indicated that the $-173 \mathrm{C}$ allele creates a potential activator protein 4 transcription factor binding site (23), and levels of MIF expression significantly differed among -173G $>C$ genotypes in a cell type manner. Regarding CATT repeats, the 5-CATT allele was shown to be associated with lower basal and stimulated MIF promoter activity in vitro than 6-, 7- and 8-CATT alleles (24). Donn et al showed that increasing CATT repeats with the $-173 \mathrm{C}$ allele significantly increased the promoter activity in a $\mathrm{T}$ lymphoblast cell line (23). Thus, the $-173 \mathrm{C}$ allele and 7-CATT seemed to promote the production of MIF, although there is no clear relationship between these polymorphisms and the transcriptional regulation of the MIF gene. Baugh et al reported the correlation of the 5/5-CATT repeat with low disease severity in rheumatoid arthritis patients (53), and Hizawa et al also reported an increased risk of non-5-CATT carriers for atopy (45). Donn et al demonstrated that the -173C-7-CATT haplotype is of importance in the susceptibility to psoriasis (44). We have recently shown that both the 7/7-CATT repeat and the $-173 \mathrm{C} / \mathrm{C}$ genotypes, as well as $H$. pylori infection and elder age, were significantly associated with the development of gastric mucosal atrophy. In addition, we have also shown that the 5-CATT carriers had a reduced risk of gastric cancer, especially the diffuse type cancer, and $-173 \mathrm{C}$ carriers and the number of 7-CATT alleles were also positively correlated with the risk of gastric cancer in older subjects and intestinal type histopathology.

However, our present result showed that 5-CATT repeat carrier, which is associated with the lower basal and stimulated MIF promoter activity, increased, but not decreased risk of CIHM of DAP-kinase and CIHM high. While, the 6-CATT repeat carrier reduced risk of CIHM of p16, CDH1, DAPkinase and CIHM high. As for $-173 \mathrm{G}>\mathrm{C}$ genotypes, we did not find significant association with CIHM. Although our observation indicates that the MIF-794-CATT repeat polymorphism, rather than the $-173 \mathrm{G}>\mathrm{C}$ polymorphism influences the risk of CIHM in the human gastric mucosa, why the 5-CATT repeat carrier increases the risk of CIHM needs to be explained.

Concerning the IL-17A and IL-17Fa polymorphisms, we did not find any significant association between IL-17A $(-197 \mathrm{G}>\mathrm{A})$ and IL-17F $(7488 \mathrm{~T}>\mathrm{C})$ polymorphisms and CIHM status. Although IL-17 have a significant role in the inflammatory response to $H$. pylori infection $(25,28,30)$, IL$17 \mathrm{~A}$ and IL-17Fa polymorphisms may not influence the risk of methylation related carcinogenesis.

In conclusion, we have shown that, MIF-5-CATT repeat carrier is associated with higher risk of CIHM especially for DAP-kinase and CIHM high. Furthermore, the 6-CATT repeat carrier is associated with reduced risk of CIHM especially for p16, CDH1, DAP-kinase and CIHM high. The present results provided the first evidence that the genetic polymorphisms of MIF may be involved in DNA methylation in human gastric mucosa. However, our data did not provide the detailed mechanisms of MIF-794-CATT repeat polymorphism in CIHM. In addition, why the interplay between MIF-794-CATT repeat polymorphism and CIHM is different in different genes is still unexplained. Only a more extensive understanding of the regulation of methylation in relation to gene expression and carcinogenesis will allow us to fully interpret our findings.

\section{References}

1. Issa JP, Ottaviano YL, Celano P, Hamilton SR, Davidson NE and Baylin SB: Methylation of the oestrogen receptor $\mathrm{CpG}$ island links ageing and neoplasia in human colon. Nat Genet 4: 536-540, 1994.

2. Ahuja N, Li Q, Mohan AL, Baylin SB and Issa JP: Aging and DNA methylation in colorectal mucosa and cancer. Cancer Res 23: 5489-5494, 1998

3. Rizos H, Darmanian AP, Mann GJ and Kefford RF: Two arginine rich domains in the p14ARF tumour suppressor mediate nucleolar localization. Oncogene 19: 2978-2985, 2000.

4. Tannapfel A, Busse C, Weinans L, et al: INK4a-ARF alterations and p53 mutations in hepatocellular carcinomas. Oncogene 20: 7104-7109, 2001

5. Toyota M, Ahuja N, Suzuki H, et al: Aberrant methylation in gastric cancer associated with the $\mathrm{CpG}$ island methylator phenotype. Cancer Res 59: 5438-5442 1999.

6. Kang GH, Shim YH, Jung HY, Kim WH, Ro JY and Rhyu MG: $\mathrm{CpG}$ island methylation in premalignant stages of gastric carcinoma. Cancer Res 61: 2847-2851, 2001.

7. Chan AO, Lam SK, Wong BC, et al: Promoter methylation of E-cadherin gene in gastric mucosa associated with Helicobacter pylori infection and in gastric cancer. Gut 52: 502-506, 2003.

8. Raveh T and Kimchi A: DAP kinase - a proapoptotic gene that functions as a tumor suppressor. Exp Cell Res 264: 185-192, 2001.

9. Schildhaus HU, Krockel I, Lippert H, Malfertheiner P, Roessner A and Schneider-Stock R: Promoter hypermethylation of p16INK4a, E-cadherin, O6-MGMT, DAPK and FHIT in adenocarcinomas of the esophagus, esophagogastric junction and proximal stomach. Int J Oncol 26: 1493-1500, 2005.

10. Waki T, Tamura G, Sato M, Terashima M, Nishizuka S and Motoyama T: Promoter methylation status of DAP-kinase and RUNX3 genes in neoplastic and non-neoplastic gastric epithelia. Cancer Sci 94: 360-364, 2003

11. Maekita T, Nakazawa K, Mihara M, et al: High levels of aberrant DNA methylation in Helicobacter pylori-infected gastric mucosae and its possible association with gastric cancer risk. Clin Cancer Res 12: 989-995, 2006.

12. Tahara T, Arisawa T, Shibata T, et al: Increased number of methylated $\mathrm{CpG}$ islands correlates with Helicobacter pylori infection, histological and serological severity of chronic gastritis. Eur J Gastroenterol Hepatol (In press).

13. Tahara T, Arisawa T, Shibata T, et al: Risk prediction of gastric cancer by analysis of aberrant DNA methylation in nonneoplastic gastric epithelium. Digestion 75: 54-61, 2007.

14. Kaise M, Yamasaki T, Yonezawa J, Miwa J, Ohta Y and Tajiri H: $\mathrm{CpG}$ island hypermethylation of tumor-suppressor genes in $H$. pylori-infected non-neoplastic gastric mucosa is linked with gastric cancer risk. Helicobacter 13: 35-41, 2008.

15. Nakajima T, Maekita T, Oda I, et al: Higher methylation levels in gastric mucosae significantly correlate with higher risk of gastric cancers. Cancer Epidemiol Biomarkers Prev 15: 2317-2321, 2006.

16. Issa JP: GpG-island methylation in aging and cancer. Curr Top Microbiol Immunol 249: 101-118, 2000.

17. Meyer-ter-Vehn T, Covacci A, Kist M and Pahl HL: Helicobacter pylori activates mitogen-activated protein kinase cascades and induces expression of the proto-oncogenes c-fos and c-jun. J Biol Chem 275: 16064-16072, 2000.

18. Seo JH, Lim JW, Kim H and Kim KH: Helicobacter pylori in a Korean isolate activates mitogen-activated kinase, AP-1 and $\mathrm{NF}-\kappa \mathrm{B}$ and induces chemokine expression in gastric epithelial AGS cells. Lab Invest 84: 49-62, 2004.

19. Kawaguchi M, Adachi M, Oda N, Kokubu F and Huang SK: IL-17 cytokine family. J Allergy Clin Immunol 114: 1265-1274, 2004. 
20. Kawaguchi M, Takahashi D, Hizawa N, et al: IL-17F sequence variant (His161Arg) is associated with protection against asthma and antagonizes wild-type IL-17F activity. J Allergy Clin Immunol 117: 795-801, 2006

21. Bloom BR and Bennett B: Mechanism of a reaction in vitro associated with delayed-type hypersensitivity. Science 153: 80-82, 1966.

22. Calandra T, Echtenacher B, Roy DL, et al: Protection from septic shock by neutralization of macrophage migration inhibitory factor. Nat Med 6: 164-170, 2000.

23. Donn R, Alourfi Z, De Benedetti F, et al: Mutation screening of the macrophage migration inhibitory factor gene: positive association of a functional polymorphism of macrophage migration inhibitory factor with juvenile idiopathic arthritis. Arthritis Rheum 46: 2402-2409, 2002.

24. Amoli MM, Donn RP, Thomson W, et al: Macrophage migration inhibitory factor gene polymorphism is associated with sarcoidosis in biopsy proven erythema nodosum. J Rheumatol 29: 1671-1673, 2002 .

25. Luzza F, Parrello T, Monteleone G, et al: Up-regulation of IL-17 is associated with bioactive IL-8 expression in Helicobacter pylori-infected human gastric mucosa. J Immunol 165: 5332-5337, 2000.

26. Xia HHX, Lam SK, Huang XR, et al: Helicobacter pylori infection is associated with increased expression of macrophage migration inhibitory factor by epithelial cells, $T$ cells and macrophages in gastric mucosa. J Infect Dis 190: 293-302, 2004.

27. Arisawa T, Tahara T, Shibata T, et al: Functional polymorphisms in the promoter region of macrophage migration inhibitory factor and chronic gastritis. Int J Mol Med 20: 539-544, 2007.

28. Arisawa $\mathrm{T}$, Tahara $\mathrm{T}$, Shibata $\mathrm{T}$, et al: Association between genetic polymorphisms in interleukin-17A and $-17 \mathrm{~F}$ gene and gastro-duodenal ulcer diseases. Scand J Gastroenterol (In press).

29. Arisawa T, Tahara T, Shibata T, et al: Functional promoter polymorphisms of the macrophage migration inhibitory factor gene in gastric carcinogenesis. Oncol Rep 19: 223-228, 2008.

30. Shibata T, Tahara T, Arisawa T and Hirata I: Genetic polymorphisms of interleukin-17A and $-17 \mathrm{~F}$ gene in gastric carcinogenesis. Hum Immunol (In press).

31. Tahara T, Shibata T, Nakamura M, et al: MTHFR 677 T carrier influences the methylation status of $H$. pylori infected gastric mucosa in older subjects. Dig Dis Sci (In press).

32. Esteller M, Tortola S, Toyota M, et al: Hypermethylationassociated inactivation of p14(ARF) is independent of p16(INK4a) methylation and p53 mutational status. Cancer Res 60: 129-133, 2000.

33. Herman JG, Graff JR, Myöhänen S, Nelkin BD and Baylin SB: Methylation-specific PCR: a novel PCR assay for methylation status of CpG islands. Proc Natl Acad Sci USA 93: 9821-9826, 1996.

34. Katzenellenbogen RA, Baylin SB and Herman JG: Hypermethylation of the DAP-kinase $\mathrm{CpG}$ island is a common alteration in B-cell malignancies. Blood 93: 4347-4353, 1999.

35. Kang GH, Lee HJ, Hwang KS, Lee S, Kim JH and Kim JS: Aberrant $\mathrm{CpG}$ island hypermethylation of chronic gastritis, in relation to aging, gender, intestinal metaplasia, and chronic inflammation. Am J Pathol 163: 1551-1556, 2003.

36. Bloom BR and Bennett B: Mechanism of a reaction in vitro associated with delayed-type hypersensitivity. Science 153: 80-82, 1966.
37. David JR: Delayed hypersensitivity in vitro: its mediation by cell-free substances formed by lymphoid cell-antigen interaction. Proc Natl Acad Sci USA 56: 72-77, 1966.

38. Leech M, Metz C, Hall P, et al: Macrophage migration inhibitory factor in rheumatoid arthritis: evidence of proinflammatory function and regulation by glucocorticoids. Arthritis Rheum 42: 1601-1608, 1999.

39. Bernhagen J, Calandra T and Bucala R: The emerging role of MIF in septic shock and infection. Biotherapy 8: 123-127, 1995.

40. Donnelly SC, Bucala R, Metz CN, et al: Macrophage migration inhibitory factor and acute lung injury. Chest 116: S111, 1999.

41. Tulic MK, Wale JL, Holt PG and Sly PD: Modification of the inflammatory response to allergen challenge after exposure to bacterial lipopolysaccharide. Am J Respir Cell Mol Biol 22: 604-612, 2000

42. Gereda JE, Leung DY, Thatayatikom A, et al: Relation between house-dust endotoxin exposure, type-1 T-cell development, and allergen sensitization in infants at high risk of asthma. Lancet 355: 1680-1683, 2000

43. Plant BJ, Gallagher CG, Bucala R, et al: Cystic fibrosis, disease severity, and a macrophage migration inhibitory factor polymorphism. Am J Respir Crit Care Med 172: 1412-1415, 2005.

44. Donn RP, Plant D, Jury F, et al: Macrophage migration inhibitory factor gene polymorphism is associated with psoriasis. J Invest Dermatol 123: 484-487, 2004.

45. Hizawa N, Yamaguchi E, Takahashi D, Nishihara J and Nishimura M: Functional polymorphisms in the promoter region of macrophage migration inhibitory factor and atopy. Am J Respir Crit Care Med 169: 1014-1018, 2004.

46. Huang XR, Chun HCW, Chen YX, et al: Macrophage migration inhibitory factor is an important mediator in the pathogenesis of gastric inflammation in rats. Gastroenterology 121: 619-630, 2001.

47. He XX, Yang J, Ding YW, Liu W, Shen QY and Xia HH: Increased epithelial and serum expression of macrophage migration inhibitory factor (MIF) in gastric cancer: potential role of MIF in gastric carcinogenesis. Gut 55: 797-802, 2006.

48. Bamford KB, Fan X, Crowe SE, et al: Lymphocytes in the human gastric mucosa during Helicobacter pylori have a $\mathrm{T}$ helper cell 1 phenotype. Gastroenterology 88: 70-74, 1998.

49. Calandra T, Bernhagen J, Mitchell RA and Bucala R: Macrophage is an important and previously unrecognized source of macrophage-migration inhibitory factor. J Exp Med 179: 1895-1902, 1994.

50. Bacher M, Mets CN, Calandra T, et al: An essential regulatory role for macrophage migration inhibitory factor in T-cell activation. Proc Natl Acad Sci USA 93: 7849-7854, 1996.

51. Benigni F, Atsumi T, Calandra T, et al: The proinflammatory mediator macrophage migration inhibitory factor induces glucose catabolism in muscle. J Clin Invest 106: 1291-1300, 2000.

52. Abe R, Peng T, Sailors J, Bucala R and Metz CN: Regulation of the CTL response by macrophage migration inhibitory factor. J Immunol 166: 747-753, 2001

53. Baugh JA, Chitnis S, Donnelly SC, et al: A functional promoter polymorphism in the macrophage migration inhibitory factor (MIF) gene associated with disease severity in rheumatoid arthritis. Genes Immun 3: 170-176, 2002. 